Supporting Information for

\title{
Structural Factors Influencing Linear M-H-M Bonding in Bis(dialkylphosphino)methane Complexes of Nickel
}

\author{
William S. Tyree, ${ }^{\dagger}$ David A. Vicic,,$^{\dagger *}$ Paula M. B. Piccoli ${ }^{\S}$, and Arthur J. \\ Schultz ${ }^{\S *}$ \\ Department of Chemistry and Biochemistry, University of Arkansas, Fayetteville, AR \\ 72701 and the Intense Pulsed Neutron Source, Argonne National Laboratory, Argonne, \\ IL 60439.
}

$\S$ University of Arkansas
Argonne National Laboratory 
General Experimental Methods: All manipulations were performed using standard Schlenk techniques or in a nitrogen-filled dry box, unless otherwise noted. Solvents were distilled from $\mathrm{Na}$ /benzophenone or $\mathrm{CaH}_{2}$. All reagents were used as received from commercial vendors unless otherwise noted. Aluminum oxide (activated, neutral, Brockmann I, $\sim 150$ mesh) was dried at $200{ }^{\circ} \mathrm{C}$ under vacuum for two days prior to use. Elemental analyses were performed by Desert Analytics. A Rigaku MSC Mercury/AFC8 diffractometer was used for X-ray structural determinations. (dippm) $\mathrm{NiCl}_{2}$ was prepared according to a previously published procedure. ${ }^{1}$ (dcpm) $\mathrm{NiBr}_{2}$ was synthesized by the procedure used to prepare the closely related (dippm) $\mathrm{NiBr}_{2} .{ }^{2}$

Synthesis of Compound 3: To a suspension of (dippm) $\mathrm{NiCl}_{2}$ in $125 \mathrm{~mL}$ benzene was added four equivalents of $\mathrm{Bu}_{3} \mathrm{SnH}$. The suspension was stirred at room temperature for $17 \mathrm{~h}$ in the dark. The volatiles were then removed on a high vacuum line, and the residue was washed with copious amounts of pentane. The remaining solids were then extracted with benzene and filtered. The benzene was removed under vacuum leaving a green solid. Yield: $200 \mathrm{mg}, 22 \%$. Product is paramagnetic. Anal. Calcd for $\mathrm{C}_{26} \mathrm{H}_{61} \mathrm{Cl}_{2} \mathrm{Ni}_{2} \mathrm{P}_{4}$ : $45.61(45.52) \% \mathrm{C} ; 8.77(8.96) \% \mathrm{H}$. Crystals of 3 for solid-state studies (X-ray and neutron) were grown from slow diffusion of pentane into THF solutions of 3.

Synthesis of Compound 4: To a suspension of (dcpm) $\mathrm{NiBr}_{2}$ in $100 \mathrm{~mL}$ THF was added a THF solution of 1-adamantylzinc bromide $(0.5 \mathrm{M})$ at room temperature. The mixture was stirred for $12 \mathrm{~h}$, at which time the solvents were removed under vacuum. The product was extracted with benzene and filtered over a frit packed with alumina. The benzene was removed under reduced pressure. The product was washed with a copious amount of pentane, filtered, and dried to give a green powder. Yield: $443 \mathrm{mg}, 56 \%$. Product is paramagnetic. Anal. Calcd for $\mathrm{C}_{50} \mathrm{H}_{93} \mathrm{Br}_{2} \mathrm{Ni}_{2} \mathrm{P}_{4}$ : 54.95 (54.83) \%C; 8.46 (8.56) $\% \mathrm{H}$. Crystals of $\mathbf{4}$ for solid-state studies (X-ray) were grown from slow diffusion of pentane into THF solutions of 4.

\section{References for synthetic work:}

1 Scott, F.; Krueger, C.; Betz, P. J. Organomet. Chem. 1990, 387, 113-21.

2. Anderson, T. J.; Vicic, D. A. Organometallics 2004, 23, 623-625. 
Neutron data collection for Compound 3. Neutron diffraction data were obtained at the Intense Pulsed Neutron Source (IPNS) at Argonne National Laboratory using the time-of-flight Laue single-crystal diffractometer (SCD). At the IPNS, pulses of protons are accelerated into a heavy-element target 30 times a second to produce pulses of neutrons by the spallation process. Exploiting the pulsed nature of the source, neutron wavelengths are determined by time-of-flight based on the de Broglie equation $\lambda=$ $(h / m) \cdot(t / l)$, where $h$ is Planck's constant, $m$ is the neutron mass, and $t$ is the time-of-flight for a flight path $l$, so that the entire thermal spectrum of neutrons can be used. With two position-sensitive area detectors and a range of neutron wavelengths, a solid volume of reciprocal space is sampled with each stationary orientation of the sample and the detectors. The SCD has two ${ }^{6} \mathrm{Li}$-glass scintillation position-sensitive area detectors, each with active areas of $15 \times 15 \mathrm{~cm}^{2}$ and a spatial resolution of $<1.5 \mathrm{~mm}$. One of the detectors is centered at a scattering angle of $75^{\circ}$ and a crystal-to-detector distance of 23 $\mathrm{cm}$, and the second detector is at $120^{\circ}$ and $18 \mathrm{~cm}$. Details of the data collection and analysis procedures have been published previously.

A crystal of $\left[(\text { dippm })_{2} \mathrm{Ni}_{2} \mathrm{Cl}_{2}(\mu-\mathrm{H})\right](\mathbf{1})$, with approximate dimensions of $3 \times 2 \times$ $0.5 \mathrm{~mm}^{3}$ and a weight of $3.9 \mathrm{mg}$, was coated with a fluorocarbon grease in a He gas filled glovebag, wrapped in aluminum foil and glued to an aluminum pin that was mounted on the cold stage of a closed-cycle helium refrigerator under flowing $\mathrm{N}_{2}$. The crystal was then cooled to $40 \pm 1 \mathrm{~K}$. For each setting of the diffractometer angles, data were stored in three-dimensional histogram form with coordinates $x, y, t$ corresponding to horizontal and vertical detector positions and the time-of-flight, respectively. An auto-indexing algorithm was used to obtain an initial orientation matrix from the peaks in three preliminary histograms measured for 60 minutes each. This unit cell approximately matched the previously reported X-ray unit cell indicating that the neutron sample was the correct material. For intensity data collection, runs of 7 hours per histogram were initiated for the data set. Settings were arranged at $\chi$ and $\varphi$ values suitable to cover at least one unique quadrant of reciprocal space (Laue symmetry $2 / \mathrm{m}$ ). With the above counting times, 16 histograms were completed in the 5 days available for the experiment. Bragg peaks in the recorded histograms were indexed and integrated using individual orientation matrices for each histogram, to allow for any misalignment of the sample. 
Intensities were integrated about their predicted locations and were corrected for the Lorentz factor, the incident spectrum, and the detector efficiency. A wavelengthdependent spherical absorption correction was applied using cross sections from Sears for the nonhydrogen atoms and from Howard et al. for the hydrogen atoms $\left(\mu\left(\mathrm{cm}^{-1}\right)=1.69\right.$ $+1.38 \lambda$ ). Symmetry related reflections were not averaged since different extinction factors are applicable to reflections measured at different wavelengths.

Refinement. The GSAS software package was used for structural analysis. The atomic positions of the X-ray diffraction structure, except for $\mathrm{Ha}$, were used as a starting model in the refinement. Hydrogen atom Ha was clearly located from a Fourier difference map during the isotropic stages of refinement. The refinement was based on $F^{2}$ with a minimum $d$-spacing of $0.5 \AA$. Weights were assigned as $w\left(F_{o}^{2}\right)=1 /$ [ $\left(\sigma\left(F_{o}^{2}\right)\right.$ $\left.+\left(0.002 * F_{o}^{2}\right)\right]^{2}$ where $\sigma^{2}\left(F_{o}^{2}\right)$ is the variance based on counting statistics. In the final refinement all atoms, including hydrogen atoms, except for atoms P4, C1, H23a and H24a, were refined with anisotropic displacement parameters (vide infra). After final refinement the maximum peak of unmodeled scattering density in the difference Fourier map was $0.525 \mathrm{fm} \AA^{-3}$ which compares to approximately $6 \%$ of the peak height of atom Ni1 in a Fourier map. Omission of Ha from the calculation resulted in a higher $R_{w}$ value of 0.167 and a negative difference Fourier peak of $-0.767 \mathrm{fm} \AA^{-3}$ at the position of Ha. Data collection and refinement parameters are summarized in Table S1.

Description of the structure. Even with long counting times (7 hours per histogram) a low data( $>3 \sigma)$ :parameter ratio of 3.1 was achieved. One of the results from this was that the anisotropic displacement parameters for the hydrogen atoms had physically unreasonable values, and the atoms $\mathrm{P} 4, \mathrm{C} 1, \mathrm{H} 23 \mathrm{a}$ and $\mathrm{H} 24 \mathrm{a}$ became nonpositive definite. To help with the low data to parameter ratio, the hydrogen atoms (excepting Ha) were restrained to lie 1.09(1) $\AA$ from the carbon atom to which they are bound. The anisotropic displacement parameters of the hydrogen atoms stabilized after this restraint was applied. Atoms P4, C1, H23a and H24a were refined with isotropic displacement parameters in the final refinements. 
The molecular structure of $\mathbf{3}$ is shown in Figures $\mathrm{S} 1$ and $\mathrm{S} 2$. Immediate similarities to the previously reported $\left[(\operatorname{dippm})_{2} \mathrm{Ni}_{2} \mathrm{Br}_{2}(\mu-\mathrm{H})\right]$ are evident, especially the linear relationship between the chloride, nickel and hydride atoms. Bond distances and angles for 3 are reported in Tables S2 and S3; a complete list is included with the appended material. Upon substitution of $\mathrm{Br}$ for $\mathrm{Cl}$, the Ni1-Ni2 distance increases by $0.022 \AA$ to $3.227(5) \AA$. The same asymmetry of the hydride ligand is seen; Ha is closer to Ni1 than to Ni2 by $0.039(23) \AA$. The angles for the atoms that lie along the Ni-Ni axis are $177.5(11)^{\circ}$ for $\mathrm{Ni} 1-\mathrm{Ha}-\mathrm{Ni} 2,176.5(2)^{\circ}$ for $\mathrm{Cl} 1-\mathrm{Ni} 1-\mathrm{Ni} 2$ and $178.0(2)^{\circ}$ for $\mathrm{Cl} 2-\mathrm{Ni} 2-$ Ni1, all of which compare favorably with the $\mathrm{Br}$ analogue. The angles about each nickel atoms are very nearly square planar; the dihedral angle between the P1-Ni1-P3 and P2Ni2-P4 planes is $156(3)^{\circ}$. Figure S3 shows the linearity of the Cl1-Ni1-Ha-Ni2-Cl2 axis as well as the dihedral angle between $\mathrm{P}-\mathrm{Ni}-\mathrm{P}$ bonds. .

Figure S4 is a plot of the difference Fourier map on exclusion of Ha from the least squares refinement. The satellite peaks in Figure S4 are at the level of noise in the map; however it is clear that only one peak maximum is seen over the peak region. The satellite peaks could be due to thermal motion. Refinement of the fractional occupancy of Ha results in an occupancy over the site of 1.03 and no serious disorder is indicated.

\section{References for structural work.}

1. Schultz, A. J. S., K.; Teller, R. G.; Williams, J. M.; Lukehart, C. M., J. Am. Chem. Soc. 1984, 106, 999-1003.

2. $\quad$ Schultz, A. J., Trans. Am. Crystallogr. Assoc. 1987, 23, 61-69.

3. Schultz, A. J.; Van Derveer, D. G.; Parker, D. W.; Baldwin, J. E., Acta Cryst. C 1990, 46, 276-279.

4. Jacobson, R. A., J. Appl. Cryst. 1976, 19, 283-286.

5. Sears, V. F., In Methods of Experimental Physics, Vol. 23, Neutron Scattering, Part A. ed.; Academic Press: Orlando, FL, 1986; 'Vol.' p 521-550.

6. Larson, A. C.; Von Dreele, R. B. General Structure Analysis System--GSAS, Los Alamos National Laboratory, 2000.

7. Vicic, D. A.; Anderson, T. J.; Cowan, J. A.; Schultz, A. J., J. Am. Chem. Soc. 2004, 126, 8132-8133.

8. Kriley, C. E.; Wooley, C. J.; Krepps, M. K.; Popa, E. M.; Fanwick, P. E.; Rothwell, I. P., Inorg. Chim. Acta 2000, 300-302, 200-205.

9. Bondi, A., J. Phys. Chem. 1964, 68, 441. 
10. Desiraju, G. R., Hydrogen Bridges in Crystal Engineering: Interactions without Borders. Acc. Chem. Res. 2002, 35, 565-573.

11. Seghete, D. Computational Study of a Novel Dinuclear Metal Complex. Honors Thesis, University of Arkansas, 2005. 
Table S1. Crystal data and structure refinement parameters for $\mathbf{3}$ from neutron diffraction.

$\begin{array}{ll}\text { formula } & \mathrm{C}_{26} \mathrm{H}_{61} \mathrm{Cl}_{2} \mathrm{Ni}_{2} \mathrm{P}_{4} \\ \text { fw } & 685.956 \\ \text { temperature, } \mathrm{K} & 40(1) \\ \text { crystal system } & \text { Monoclinic } \\ \text { space group } & P{ }_{1} / c \\ a, \AA & 14.341(2) \\ b, \AA & 14.882(3) \\ c, \AA & 16.212(2) \\ \beta,{ }^{\circ} & 93.98(1) \\ V, \AA^{3} & 3451.6(9) \\ Z & 4 \\ d_{\text {calc }}, \mathrm{g} \mathrm{cm}^{-3} & 1.32 \\ \text { size, mm } & \\ \text { radiation } & 3 \times 2 \times 0.5 \\ \text { data collection technique } & \text { neutrons } \\ \mu(\lambda), \mathrm{cm}^{-1} & \text { time-of-flight Laue } \\ \text { max, min transmission } & 1.69+1.38 \lambda \\ \text { extinction parameter } & 0.7334,0.2062 \\ d_{\text {min }}, \AA & 5.78(6) * 10^{-6} \\ \text { no. of reflns } & 0.5 \\ \text { no. of reflns }(I>3 \sigma(I))^{\mathrm{a}} & 5269 \\ \text { no. of parameters refined } & 2680 \\ \text { refinement method } & 868 \\ R \text { indices } R_{\mathrm{w}}\left(F^{2}\right)^{\mathrm{b}}, R\left(F^{2}\right)^{\mathrm{c}} & \text { Full-matrix least-squares on } F^{2} \\ \text { goodness-of-fit } & 0.147,0.155 \\ & 1.29 \\ & \end{array}$

${ }^{a}$ Outliers with $\left|F_{\mathrm{o}}{ }^{2} / F_{\mathrm{c}}{ }^{2}\right|>2$ and $\left|F_{\mathrm{c}}{ }^{2} / F_{\mathrm{o}}{ }^{2}\right|>2$ were rejected.

${ }^{\mathrm{b}} R_{w}\left(F^{2}\right)=\left\{\sum\left[w\left(F_{\mathrm{o}}{ }^{2}-F_{c}{ }^{2}\right)^{2}\right] / \sum\left[w\left(F_{o}{ }^{2}\right)^{2}\right]\right\}^{1 / 2}$

${ }^{\mathrm{c}} R\left(F^{2}\right)=\Sigma\left|F_{o}{ }^{2}-F_{c}{ }^{2}\right| / \Sigma\left|F_{o}{ }^{2}\right|$ 
Table S2. Selected bond distances $(\AA)$ for 3.

\begin{tabular}{llll}
\hline Ni1 - C11 & $2.250(6)$ & P4 - C23 & $1.844(9)$ \\
Ni1 - P1 & $2.218(8)$ & P4 - C26 & $1.859(11)$ \\
Ni1 - P3 & $2.201(8)$ & $\mathrm{C} 1-\mathrm{C} 2$ & $1.532(9)$ \\
Ni1 - Ha & $1.594(17)$ & $\mathrm{C} 1-\mathrm{C} 3$ & $1.484(8)$ \\
Ni2 - C12 & $2.279(6)$ & $\mathrm{C} 4-\mathrm{C} 5$ & $1.530(8)$ \\
Ni2 - P2 & $2.222(9)$ & $\mathrm{C} 4-\mathrm{C} 6$ & $1.542(10)$ \\
Ni2 - P4 & $2.196(8)$ & $\mathrm{C} 7-\mathrm{C} 8$ & $1.527(9)$ \\
Ni1 - Ni2 & $3.227(5)$ & $\mathrm{C} 7-\mathrm{C} 9$ & $1.532(8)$ \\
Ni2 - Ha & $1.633(16)$ & $\mathrm{C} 10-\mathrm{C} 11$ & $1.538(10)$ \\
P1 - C1 & $1.838(8)$ & $\mathrm{C} 10-\mathrm{C} 12$ & $1.533(9)$ \\
$\mathrm{P} 1-\mathrm{C} 4$ & $1.862(9)$ & $\mathrm{C} 14-\mathrm{C} 15$ & $1.544(8)$ \\
P1 - C13 & $1.838(11)$ & $\mathrm{C} 14-\mathrm{C} 16$ & $1.521(9)$ \\
$\mathrm{P} 2-\mathrm{C} 7$ & $\mathrm{C} 17-\mathrm{C} 18$ & $1.546(9)$ \\
$\mathrm{P} 2-\mathrm{C} 10$ & $1.845(10)$ & $\mathrm{C} 17-\mathrm{C} 19$ & $1.516(10)$ \\
$\mathrm{P} 2-\mathrm{C} 13$ & $1.882(12)$ & $\mathrm{C} 20-\mathrm{C} 21$ & $1.519(8)$ \\
$\mathrm{P} 3-\mathrm{C} 14$ & $1.784(10)$ & $\mathrm{C} 20-\mathrm{C} 22$ & $1.519(9)$ \\
P3 - C17 & $1.853(11)$ & $\mathrm{C} 23-\mathrm{C} 24$ & $1.517(9)$ \\
P3 - C26 & $1.866(10)$ & $\mathrm{C} 23-\mathrm{C} 25$ & $1.528(9)$ \\
P4 - C20 & $1.820(10)$ & &
\end{tabular}

Table S3. Selected bond angles $\left({ }^{\circ}\right)$ for 3 .

\begin{tabular}{|c|c|c|c|}
\hline Ni1 - Ha - Ni2 & $177.5(11)$ & $\mathrm{Ni} 2-\mathrm{P} 4-\mathrm{C} 23$ & $115.5(5)$ \\
\hline Cl1 - Ni1 - P1 & $91.65(27)$ & $\mathrm{Ni} 2-\mathrm{P} 4-\mathrm{C} 26$ & $118.9(4)$ \\
\hline Cl1 - Ni1 - P3 & $92.79(28)$ & $\mathrm{C} 20-\mathrm{P} 4-\mathrm{C} 23$ & $103.8(4)$ \\
\hline Cl1 - Nil - Ha & $176.7(6)$ & $\mathrm{C} 20-\mathrm{P} 4-\mathrm{C} 26$ & $101.3(5)$ \\
\hline P1 - Ni1 - P3 & $175.5(4)$ & $\mathrm{C} 23-\mathrm{P} 4-\mathrm{C} 26$ & $103.1(4)$ \\
\hline P1 - Ni1 - Ha & $86.6(6)$ & $\mathrm{P} 1-\mathrm{C} 1-\mathrm{C} 2$ & $109.9(4)$ \\
\hline P3 - Ni1 - Ha & $88.9(6)$ & $\mathrm{P} 1-\mathrm{C} 1-\mathrm{C} 3$ & $114.7(4)$ \\
\hline $\mathrm{Cl} 2-\mathrm{Ni} 2-\mathrm{P} 2$ & $91.98(31)$ & $\mathrm{C} 2-\mathrm{C} 1-\mathrm{C} 3$ & $110.7(5)$ \\
\hline $\mathrm{Cl} 2-\mathrm{Ni} 2-\mathrm{P} 4$ & $93.18(26)$ & $\mathrm{P} 1-\mathrm{C} 4-\mathrm{C} 5$ & $108.2(4)$ \\
\hline $\mathrm{Cl} 2$ - Ni2 - Ha & $176.9(6)$ & P1 - C4 - C6 & $114.3(5)$ \\
\hline P2 - Ni2 - P4 & $174.8(4)$ & $\mathrm{C} 5-\mathrm{C} 4-\mathrm{C} 6$ & $109.3(5)$ \\
\hline P2 - Ni2 - Ha & $85.4(6)$ & $\mathrm{P} 2-\mathrm{C} 7-\mathrm{C} 8$ & $110.2(5)$ \\
\hline P4 - Ni2 - Ha & $89.4(6)$ & P2 - C7 - C9 & $113.6(4)$ \\
\hline Ni1 - P1 - C1 & $116.0(4)$ & $\mathrm{C} 8-\mathrm{C} 7-\mathrm{C} 9$ & $111.0(4)$ \\
\hline Ni1 - P1 - C4 & $109.5(4)$ & P2 - C10 - C11 & $114.2(5)$ \\
\hline Ni1 - P1 - C13 & $119.9(4)$ & $\mathrm{P} 2-\mathrm{C} 10-\mathrm{C} 12$ & $109.8(6)$ \\
\hline $\mathrm{C} 1-\mathrm{P} 1-\mathrm{C} 4$ & $104.1(4)$ & $\mathrm{C} 11-\mathrm{C} 10-\mathrm{C} 12$ & $109.8(5)$ \\
\hline $\mathrm{C} 1-\mathrm{P} 1-\mathrm{C} 13$ & $103.4(5)$ & $\mathrm{P} 1-\mathrm{C} 13-\mathrm{P} 2$ & $118.1(5)$ \\
\hline C4 - P1 - C13 & $101.9(4)$ & P3 - C14 - C15 & $109.8(5)$ \\
\hline $\mathrm{Ni} 2-\mathrm{P} 2-\mathrm{C} 7$ & $115.4(4)$ & P3 - C14 - C16 & $115.1(5)$ \\
\hline $\mathrm{Ni2}-\mathrm{P} 2-\mathrm{C} 10$ & $110.2(4)$ & C15 - C14 - C16 & $111.4(5)$ \\
\hline $\mathrm{Ni} 2-\mathrm{P} 2-\mathrm{C} 13$ & $121.4(5)$ & P3 - C17 - C18 & $113.9(5)$ \\
\hline C7 - P2 - C10 & $104.3(6)$ & P3 - C17 - C19 & $108.1(5)$ \\
\hline C7 - P2 - C13 & $101.8(4)$ & C18 - C17 - C19 & $110.6(5)$ \\
\hline $\mathrm{C} 10-\mathrm{P} 2-\mathrm{C} 13$ & $101.8(5)$ & $\mathrm{P} 4-\mathrm{C} 20-\mathrm{C} 21$ & $109.8(4)$ \\
\hline
\end{tabular}




$\begin{array}{llll}\text { Ni1 - P3 - C14 } & 113.5(4) & \text { P4 - C20 - C22 } & 112.2(5) \\ \text { Ni1 - P3 - C17 } & 112.4(4) & \mathrm{C} 21-\mathrm{C} 20-\mathrm{C} 22 & 110.2(5) \\ \text { Ni1 - P3 - C26 } & 120.6(5) & \mathrm{P} 4-\mathrm{C} 23-\mathrm{C} 24 & 110.4(4) \\ \mathrm{C} 14-\mathrm{P} 3-\mathrm{C} 17 & 102.2(5) & \mathrm{P} 4-\mathrm{C} 23-\mathrm{C} 25 & 114.3(5) \\ \mathrm{C} 14-\mathrm{P} 3-\mathrm{C} 26 & 104.0(5) & \mathrm{C} 24-\mathrm{C} 23-\mathrm{C} 25 & 109.9(4) \\ \mathrm{C} 17-\mathrm{P} 3-\mathrm{C} 26 & 101.9(4) & \mathrm{P} 3-\mathrm{C} 26-\mathrm{P} 4 & 118.6(4) \\ \text { Ni2 - P4 - C20 } & 112.4(4) & \mathrm{C} 11-\mathrm{Ni} 1-\mathrm{N} 2 & 176.5(2) \\ & & \mathrm{C} 12-\mathrm{Ni2}-\mathrm{Ni1} & 178.0(2)\end{array}$

Table S4. Bond distances $(\AA)$ and angles $\left(^{\circ}\right)$ for $\mathrm{C}-\mathrm{H}^{\cdots} \mathrm{Cl}$ contacts closer than the sum of the van der Waals radii $(2.95 \AA)$.

\begin{tabular}{|c|c|c|c|}
\hline Cl1 - H1A & $2.705(11)$ & $\mathrm{Cl} 2-\mathrm{H} 7 \mathrm{~A}$ & $2.739(13)$ \\
\hline Cl1 - H6B & $2.734(14)$ & $\mathrm{Cl} 2-\mathrm{H} 11 \mathrm{~B}$ & $2.798(13)$ \\
\hline Cl1 - H14A & $2.642(14)$ & $\mathrm{Cl} 2-\mathrm{H} 23 \mathrm{~A}$ & $2.726(12)$ \\
\hline Cl1 - H18B & $2.866(14)$ & $\mathrm{Cl} 2-\mathrm{H} 24 \mathrm{~B}$ & $2.948(14)$ \\
\hline H1A - C11 - H6B & $67.6(4)$ & $\mathrm{H} 7 \mathrm{~A}-\mathrm{Cl} 2-\mathrm{H} 11 \mathrm{~B}$ & 63.1(4) \\
\hline $\mathrm{H} 1 \mathrm{~A}-\mathrm{Cl1}-\mathrm{H} 14 \mathrm{~A}$ & $173.4(4)$ & $\mathrm{H} 7 \mathrm{~A}-\mathrm{Cl} 2-\mathrm{H} 23 \mathrm{~A}$ & $174.2(4)$ \\
\hline $\mathrm{H} 1 \mathrm{~A}-\mathrm{Cl} 1-\mathrm{H} 18 \mathrm{~B}$ & $110.6(4)$ & $\mathrm{H} 7 \mathrm{~A}-\mathrm{Cl} 2-\mathrm{H} 24 \mathrm{~B}$ & $131.8(4)$ \\
\hline H6B - C11 - H14A & $116.7(4)$ & $\mathrm{H} 11 \mathrm{~B}-\mathrm{Cl} 2-\mathrm{H} 23 \mathrm{~A}$ & $118.7(4)$ \\
\hline H6B - Cl1 - H18B & $168.3(5)$ & $\mathrm{H} 11 \mathrm{~B}-\mathrm{Cl} 2-\mathrm{H} 24 \mathrm{~B}$ & $70.8(4)$ \\
\hline $\mathrm{H} 14 \mathrm{~A}-\mathrm{C} 11-\mathrm{H} 18 \mathrm{~B}$ & $64.1(4)$ & $\mathrm{H} 23 \mathrm{~A}-\mathrm{Cl} 2-\mathrm{H} 24 \mathrm{~B}$ & $48.64(3)$ \\
\hline C11 - H1A - C1 & $121.6(7)$ & $\mathrm{Cl} 2-\mathrm{H} 7 \mathrm{~A}-\mathrm{C} 7$ & $116.8(9)$ \\
\hline C11 - H6B - C6 & $127.9(1)$ & $\mathrm{Cl} 2-\mathrm{H} 11 \mathrm{~B}-\mathrm{C} 11$ & $135.3(1)$ \\
\hline Cl1 - H14A - C14 & $119.0(1)$ & $\mathrm{Cl} 2-\mathrm{H} 23 \mathrm{~A}-\mathrm{C} 23$ & $117.3(7)$ \\
\hline C11 - H18B - C18 & 127.1(1) & $\mathrm{Cl} 2-\mathrm{H} 24 \mathrm{~B}-\mathrm{C} 24$ & $123.5(1)$ \\
\hline
\end{tabular}




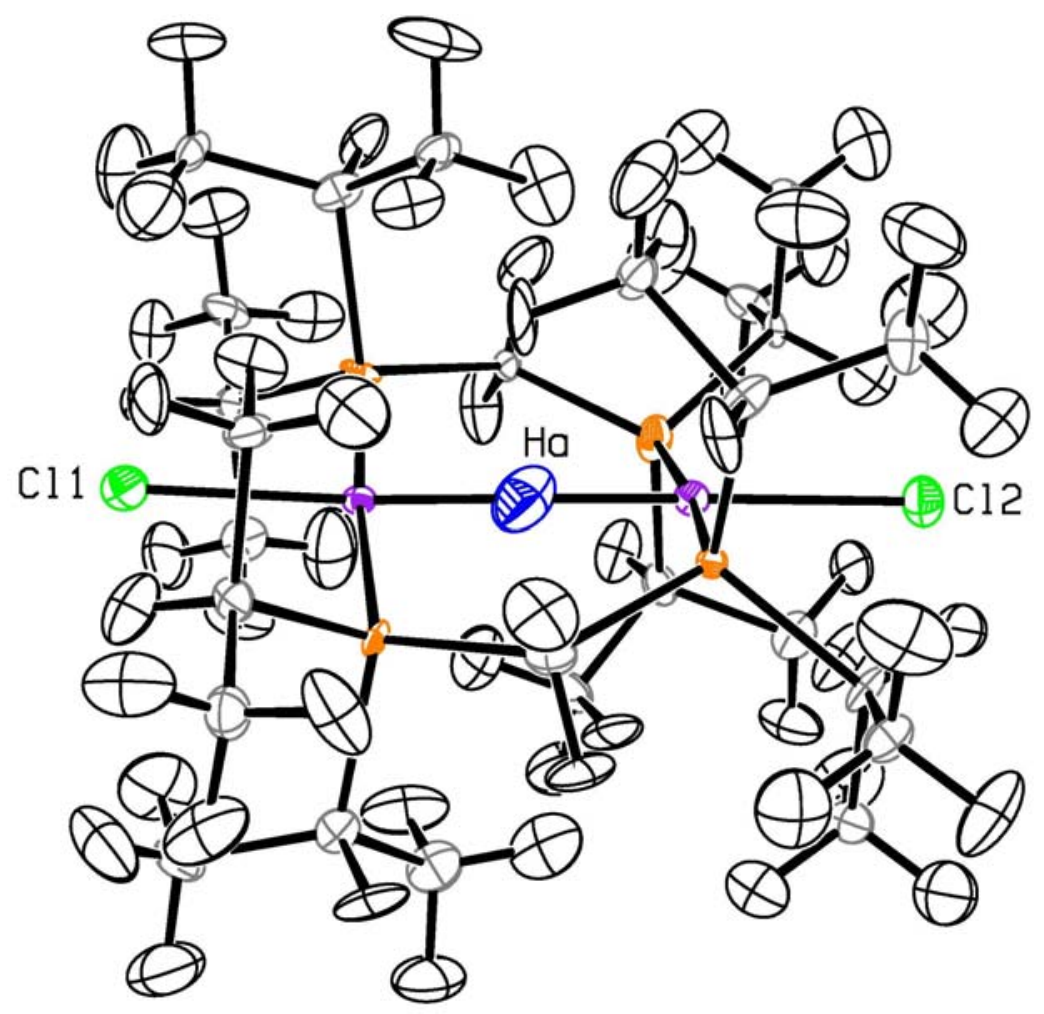

Figure S1. ORTEP of 3 showing all hydrogen atoms in the structure. Nickel is plotted in purple, phosphorus in orange, chlorine in green, carbon in gray and hydrogen in black. The bridging hydride Ha is plotted in blue for clarity. Anisotropic displacement parameters plotted at 50\%.

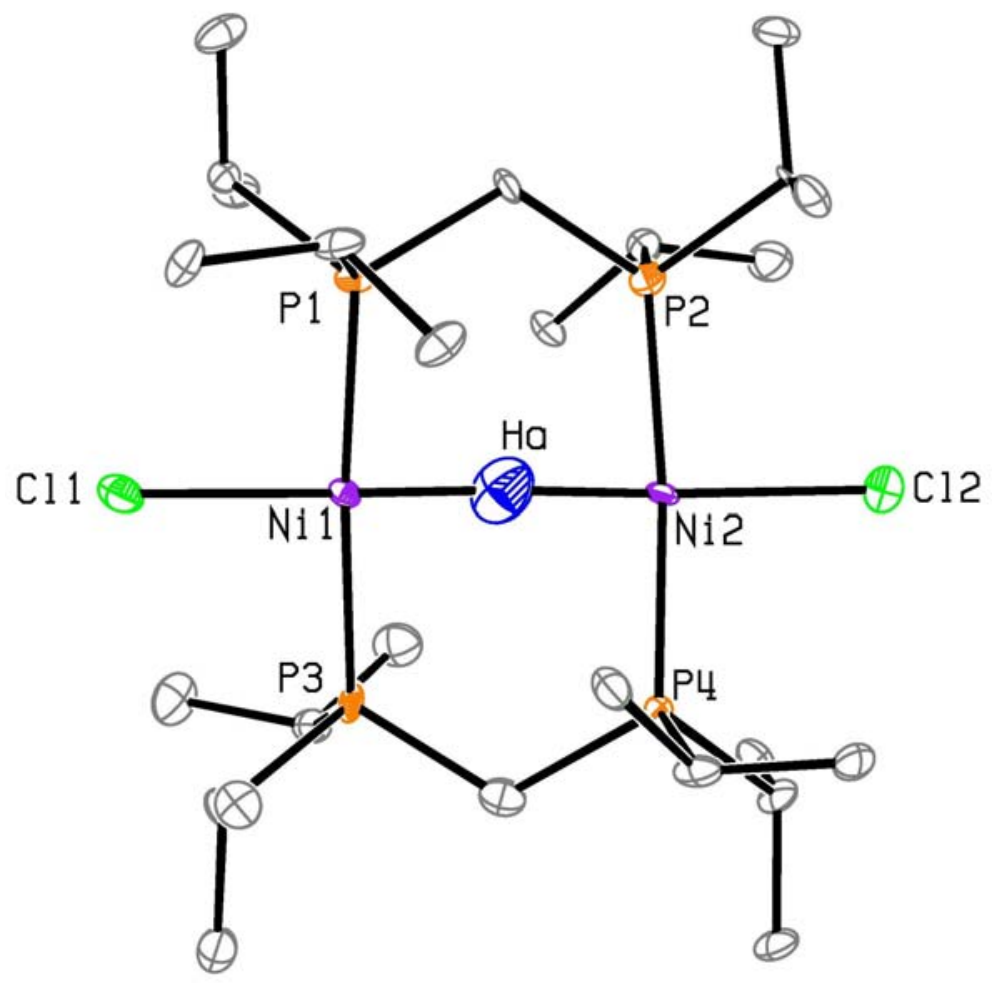

Figure S2. ORTEP of $\mathbf{3}$ showing the core of the molecule, with hydrogen atoms excepting Ha omitted for clarity. Anisotropic displacement parameters plotted at 50\%. 


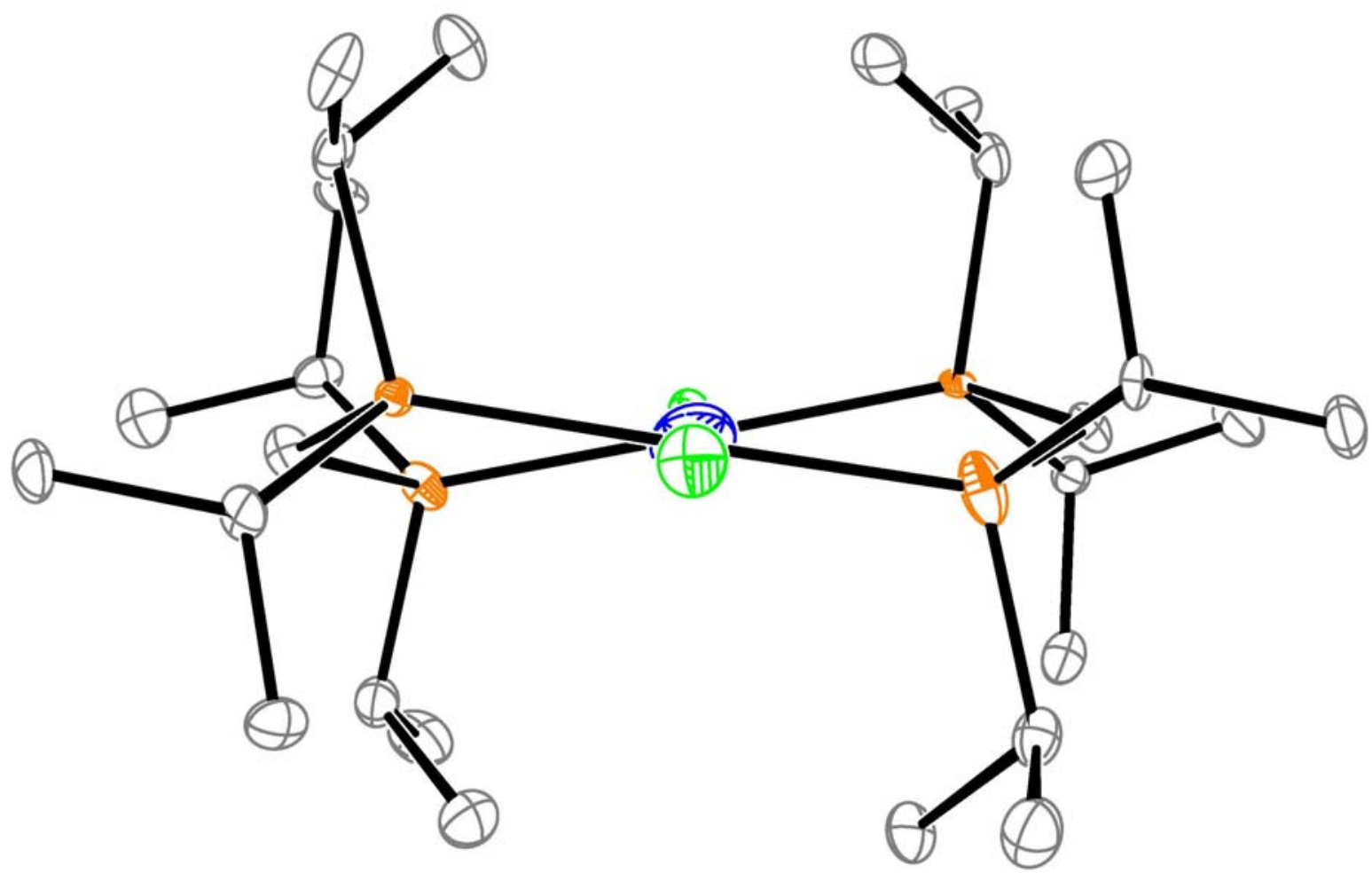

Figure S3. ORTEP of 3 viewed down the $\mathrm{Ni}-\mathrm{Ni}$ axis, showing the near-linearity of the Cl1-Ni1- $\mathrm{Ha}-$ $\mathrm{Ni} 2-\mathrm{Cl} 2$ bonds. 


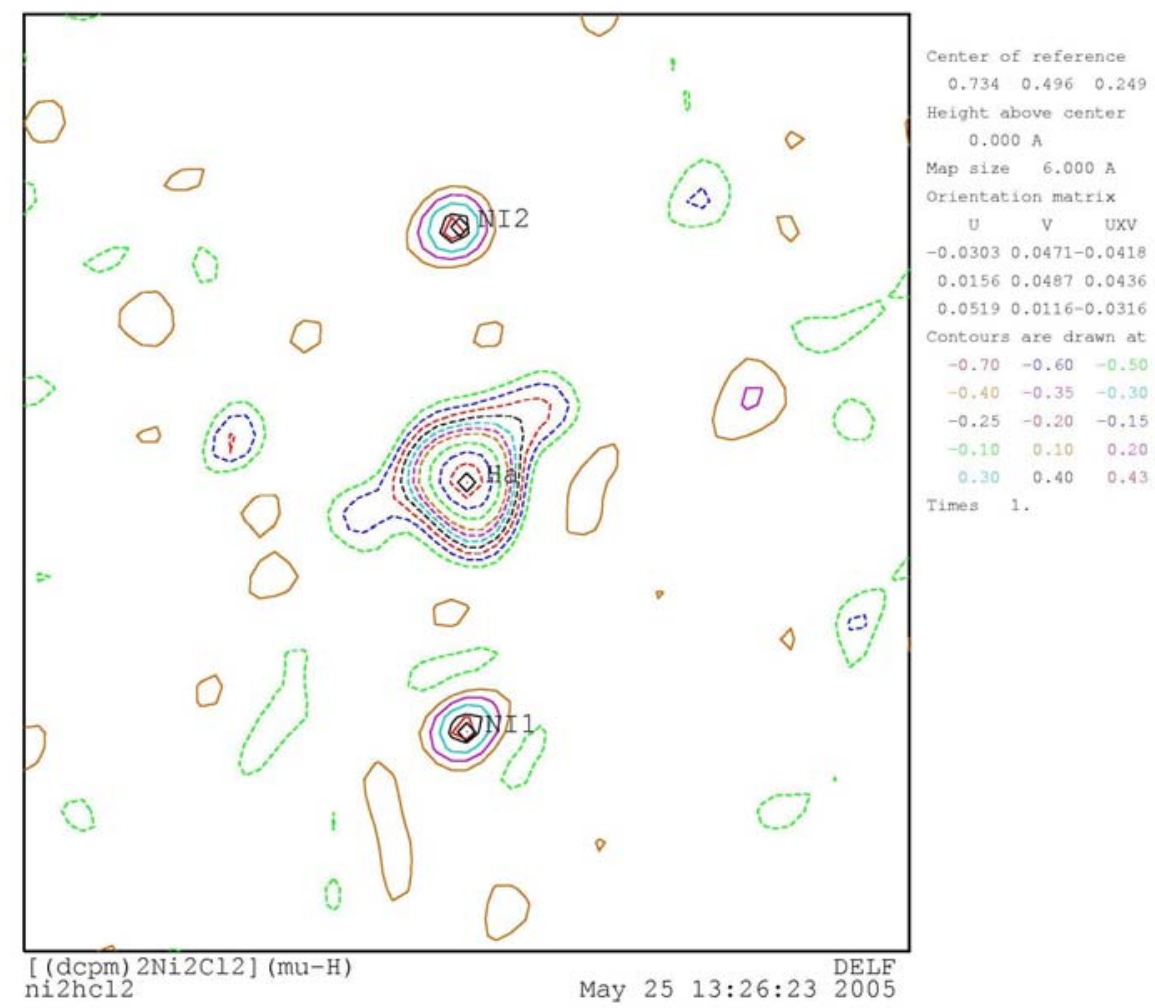

Figure S4. Difference Fourier map on omitting the bridging hydride Ha from the calculation. Negative scattering regions, indicated by dashed lines, are indicative of hydrogen which has a negative neutron scattering length. While the extensions of the contours may indicate some level of disorder, they are at the level of noise in the map and so no definitive conclusions can be drawn. Refinement of the fractional occupancy of Ha results in a value of 1.03, indicating full occupancy of the site. Map size is $6 \AA$ on an edge. 


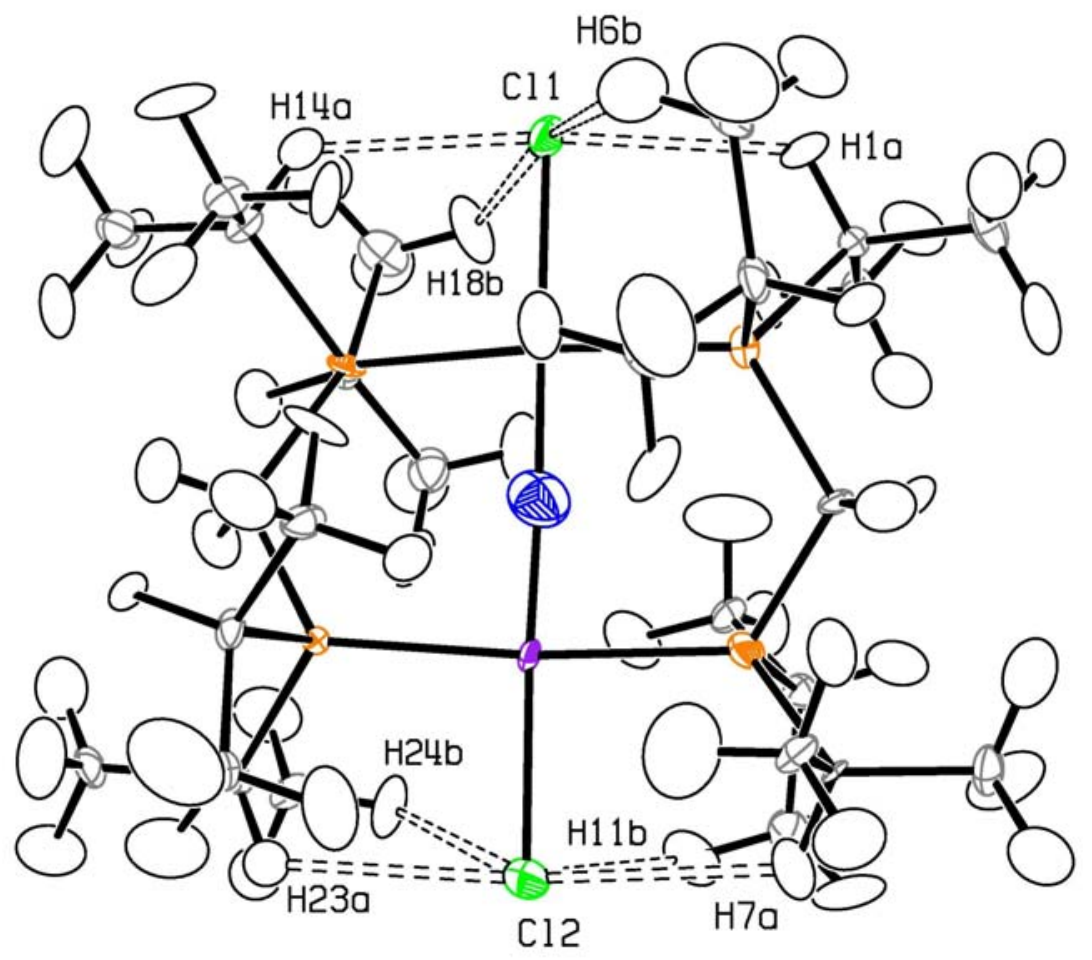

Figure S5. ORTEP of 3 illustrating those $\mathrm{C}-\mathrm{H}^{\cdots}{ }^{\cdots} \mathrm{Cl}$ contacts closer than the sum of their van der Waals radii $(2.95 \AA)$. Hydrogen bridges of this type are indicated by dashed lines. Distances and angles for these contacts are given in Table S4. Anisotropic displacement parameters are plotted at $50 \%$. 